Please quote as: Blohm, I.; Haas, P.; Peters, C.; Jakob, T. \& Leimeister, J. M. (2016): Managing Disruptive Innovation through Service Systems - The Case of Crowdlending in the Banking Industry. In: International Conference on Information Systems (ICIS), Dublin, Ireland. 


\title{
Managing Disruptive Innovation through Service Systems - The Case of Crowdlending in the Banking Industry
}

Teaching Case

\author{
Ivo Blohm ${ }^{1}$ \\ ivo.blohm@unisg.ch
}

\author{
Philipp Haas 1 \\ philipp.haas@unisg.ch \\ Thomas Jakob ${ }^{1}$ \\ thomasjakob@yahoo.com
}

\author{
Christoph Peters 1, 2 \\ christoph.peters@unisg.ch
}

\author{
${ }^{1}$ University of St. Gallen \\ Institute of Information Management \\ Unterer Graben 21, CH-900o St. Gallen, Switzerland \\ ${ }^{2}$ University of Kassel \\ Information Systems \\ Pfannkuchstr. 1, D-34121 Kassel, Germany
}

\begin{abstract}
The Internet has affected and partially radically changed the business models of traditional industries. Crowdfunding as a new concept of funding over the Internet by a large crowd has especially gained maturity. Crowdfunding offerings range from funding charitable projects or innovative gadgets to a funding alternative for start-ups or small businesses. Therefore, crowdfunding represents an innovative way to provide liquidity for illiquid markets. With regard to the banking crisis and the growing skepticism toward banks, crowdfunding is seen as a more transparent, democratic, and entertaining way of funding, which makes it highly attractive for banks. A senior innovation manager of The Bank of Switzerland (TBOS), one of Switzerland's largest and most traditional banks, recognized the disruptive and beneficial potential of crowdlending. By facing strong resentments, he developed the idea of TBOS engaging in crowdlending by collaborating with a start-up by bundling competencies in a service system.
\end{abstract}

Keywords: Crowdfunding, Crowdlending, Disruptive Innovation, Service Systems, Teaching Case 


\section{Introduction}

When Nick ${ }^{1}$ woke up on a Monday morning in summer 2015, he was excited. He had just started his new job as head of the Innovation Management team at one of the largest banks in Switzerland - The Bank of Switzerland (TBOS). Previous to this job, he worked as innovation scout in Silicon Valley for one of the leading Swiss IT companies. In Silicon Valley, he really loved the start-up spirit, the vibrant work attitude, and meeting fascinating entrepreneurs having nothing but a vision to make the world a better place day in and day out. Given this background, he seemed to be the ideal candidate for running the Innovation Management department at TBOS, where he was confronted with laborious and formal organizational processes, rigid structures, and the inertia of a traditional market incumbent. After three months of adjustment and ramp-up, he felt more and more empowered to care about his most prevalent duty - setting $T B O S$ at the forefront of digital innovations in the Swiss financial service industry.

His excitement was raised by a newspaper article that he was reading while drinking his morning coffee before driving to work: "Crowdfunding on the rise". His curiosity about this topic revived while reading the article. Nick remembered how he first heard about crowdfunding in 2012, when Pebble ${ }^{2}$, one of the first manufacturers of smart watches, tried to raise 100,000 USD via Kickstarter. The project gained large publicity, and finally, over 70,000 Internet users supported the project with more than 10 million USD. At that time, Nick recognized how Silicon Valley soaked up this new way of funding creative projects and startups. The article stated that crowdfunding started to provide funding for innovative and creative projects at their beginning while the capital givers were offered a reward for their investments. According to the article, the crowdfunding market had matured and more and more platforms offered serious alternatives to traditional bank credits. When he read that crowdfunding was also entering Europe and the British Business Bank 3 was investing 40 million British Pounds in a crowdfunding platform to issue credits to small and medium enterprises, Nick was wondering how crowdfunding might impact the Swiss financial service industry and he started to think about implications for TBOS. On his way to work, he decided to put crowdfunding on $T B O S$ 's digital innovation agenda and to assess the opportunities of crowdfunding for TBOS.

During the innovation team's meeting on that day, Nick was excited to mention his discovery. He reported about the article, the great opportunities crowdfunding might offer, and the disruptive impact this phenomenon might have on the whole financial service industry. During his report, Nick recognized the rolling eyes of Steve, the representative of TBOS's Compliance \& New Business department. Unsettled, Nick addressed Steve whether he had any objections. Steve rose to speak and explained that TBOS had already evaluated this topic several times and they had been unable to design a profitable and viable business model within TBOS due to the high regulatory complexity TBOS was facing as a bank. Bringing an own crowdfunding platform into action that meets the high quality standards of $T B O S$ would be way too expensive. Besides, TBOS's IT department would be working to capacity until 2018 due to other projects that were much more important. Steve concluded that TBOS should not waste its time with this topic again.

Nick was surprised about the strong rejection and resentment. He thanked Steve for the comment as he did not know that this topic had been examined before. Nevertheless, Nick decided he wanted to have a closer look at the previous initiative as he felt convinced that crowdfunding might bear some potential for TBOS.

\footnotetext{
${ }^{1}$ This illustrative case elaborates on experiences during a research project together with a Swiss bank. In order not to publish any details on the organizations' inner processes, or to publish any confidential information, the names of the organizations and the characters are disguised.
}

${ }^{2}$ https://www.kickstarter.com/projects/597507018/pebble-e-paper-watch-for-iphone-andandroid/description

3 https://www.fundingcircle.com/blog/2014/02/british-business-bank-lends-40m-funding-circle/ 


\section{The Crowdfunding Market}

Crowdfunding has gained huge momentum during the last few years. In the beginning, the major aim of crowdfunding was to provide funding for creative projects or innovative gimmicks. Therefore, capital seekers could promote their ideas on intermediary crowdfunding platforms and attract potential capital givers by offering them attractive rewards according to their investment volume. Possible rewards range from handwritten thank-you cards to limited or early versions of the product. This crowdfunding type is mostly referred to as reward-based crowdfunding and can be characterized by a hedonistic orientation. Over the last decade, the idea of collective funding by a crowd of capital givers has matured and additional crowdfunding types emerged. These include donation-based crowdfunding, which has an altruistic orientation and aims at funding charitable projects or NGOs. Further profit-oriented crowdfunding types emerged, such as equity-based crowdfunding, where start-ups try to collect equities by offering shares or profit participation, or crowdlending (for an overview, see Exhibit 1). In terms of funding volume, crowdlending is the most relevant crowdfunding type. In crowdlending, capital seekers make calls for the funding of loans. These loans are mostly for funding private consumption (e.g., travelling, cars, or furnishing), private purposes (education, tax payments, debt restructuring), or business purposes (current and fixed assets). Thus, the business model of crowdfunding in general allows the creation of highly specialized long-tail offerings. Therefore, a crowd of both private and institutional capital givers is addressed. For capital seekers, crowdfunding brings liquidity and funding to markets that could not be served so far, and for capital givers, it provides attractive investing alternatives. As a consequence, a broad magnitude of different crowdfunding offerings has emerged.

As Exhibit 2 shows, global crowdfunding is characterized by enormous growth and its figures multiplied each year. Crowdlending especially accelerated its growth each year and increased its importance. Compared to a more mature market such as Germany, Switzerland is still in its infancy, as shown in Exhibit 3. Up to now, the practice of crowdfunding in Switzerland has not yet picked up speed, which might indicate either unexploited market opportunities or the refusal of this new type of funding among peers. A few smaller platforms have been started aiming at collecting funding for social or creative projects at a very small scale. Recently, a local bank initiated a crowdfunding platform for supporting their regional donation activities. No major bank has engaged in crowdfunding so far. All existing platforms mostly have a strong regional focus. Further, single platforms aim at the crowdfunding of start-ups via profit shares. Due to the very low number of successfully funded start-ups and the low volume, this has not gained large attention up to now. In the crowdlending market, no platform exists so far.

\section{TBOS - An Institution in the Swiss Banking Industry}

TBOS is one of the largest and most traditional retail banks in Switzerland. It has been in business for more than a century and, as of today, employs more than 4,00O people. Today, TBOS offers most of its services via their large branch network and its main competitors are regionally based banks that are in close contact with their customers through village-based outlets. TBOS is very well perceived within Switzerland, especially for its reputation as a stable, reliable, and yet forward-looking bank. Today, TBOS's main business focuses lie in payment as well as private and retirement saving services where it acts as Swiss market leader. Half of the Swiss citizens and two thirds of the corporations in Switzerland are customers of TBOS. Even though these are great numbers, TBOS was not able to establish a comparable market share in the markets for consumer and business credits, which do currently not belong to the core of its strategy. Also, TBOS was not able to set up a compelling online business. As a consequence, $T B O S$ offers mortgage loans, credits, and also sells products through its public website, but only with limited success.

Although TBOS is charging its customers fees for transactions as well as for savings accounts, the majority of its income is generated through interest margins in the domain of saving services. This business model has been very successful for many years, but with the lack of good investment opportunities, times have become more difficult for TBOS. Additionally, as a consequence of the financial crisis in 2008, regulation guidelines are ever increasing, and being compliant with the new standards demands large investments on the side of TBOS in order to meet the new equity requirements. This puts pressure on margins, making the interest business less profitable. Therefore, TBOS is searching for opportunities to make itself more independent from what is called the core banking market. Two years ago, TBOS decided to sharpen its strategy and to embrace digitization in order to prepare itself for the future. This decision led to some heavy- 
duty investments within its core banking system, that is, the technical infrastructure processing all customer transactions and its surrounding applications. Over time, these projects started to consume large amounts of financial and human resources in order to handle their complexity. Unfortunately, due to internal competition for resources, important improvements in customer contact processes as well as many forward-oriented projects had to be delayed in order not to put the core projects at risk.

But even in times of focus, TBOS's management decided to keep an innovation process running as it understands the need for having a team that pursues opportunities outside of the standard business plan. The innovation team set up a process where new ideas can be developed and evaluated through several innovation gates. So far, most of the ideas have been brought up by TBOS's employees and a good number of these ideas were quite interesting. However, the majority of the ideas were incremental suggestions for existing products. Further, TBOS's innovation objectives suffer from the existing gap between TBOS's innovation strategy and the actual willingness and capability of the different characters and departments toward engaging and supporting innovation projects. The different mindsets of the departments hamper the creation of an innovation-friendly environment and complicate Nick's work and the discovery and exploitation of disruptive innovations.

Nick leads the Innovation Management team with about 20 employees. The task of the Innovation Management team is to explore new trends, make them tangible, and to implement them within TBOS organization. As shown in the organigram (see Exhibit 4), the Innovation Management team is organized as a staff group belonging to the corporate center. Nick reports directly to a member of the executive board, who is very open to new trends. Despite his high position, Nick himself has no decision-making power of which idea will be implemented and which resources are allocated to realize the idea. In order to implement ideas, the Innovation Management team relies on the development of internal networks and building alliances.

Maria is the leader of Product Management and has a very important and powerful position. Product Management manages TBOS's core products and is highly profit oriented. Their power lies in the longstanding, carefully built customer relationships. Therefore, they prefer the status quo and are very critical of innovation as they are afraid of jeopardizing their power and unique customer access. They only support innovations that strengthen their position.

Steve works for the Compliance \& New Business department, which is also organized as staff position in the corporate center, which employs primarily lawyers and legal advisors. As TBOS operates in a highly regulated market, their task is to evaluate and advise new business opportunities regarding their legal compliance in order to keep away any regulatory risks. In their eyes, innovations are rather risks than they represent opportunities. As they are very risk-averse they are very critical against any kind of innovation. They have regularly slowed and terminated initiatives coming from the innovation management team.

\section{Unraveling TBOS's Crowdfunding History}

After the innovation team's meeting, Nick asked Alex, one of the experienced innovation managers in his team, to support him in collecting and reviewing available information about the previous crowdfunding initiative. One week later, they met in order to discuss his findings. Alex presented that the Product Management department of TBOS had carried out a feasibility study one year ago. The study concluded that crowdlending might be the most promising type of crowdfunding for a sustainable and profitable business model, while donation- or reward-based crowdfunding might be suitable for improving the bank's image in terms of corporate social responsibility. Equity-based crowdfunding would not be feasible in the short term as TBOS had absolutely no experience and know-how in start-up financing, IPOs, and related legal and regulatory issues. Further, the study concluded that crowdlending would sustainably become established in the Swiss market and provide great opportunities for TBOS, such as the exploitation of niche markets and providing innovative products for a new generation of customers. Nevertheless, they had solely considered an in-house development of the platform and missed to take the reuse of internal processes provided by the new core banking system into account. Thus, they had failed to create a profitable business case, and as a consequence, the executives of Product Management decided to turn down the initiative. Alex reported that the authors of the feasibility study showed no interest in re-examining the potential of a crowdlending platform for TBOS. Nick was wondering about this resentment and wanted to know who had 
been responsible for the study. It was Maria, head of Product Management. Nick concluded: "Oh dear, I'll schedule a meeting with her in order to find out what the problems are."

One week later, Nick sat in Maria's office. After some small talk, Nick could not wait to get to the point and asked her why she had decided not to start a crowdlending platform. Nick explained that he thought it was a very important trend that $T B O S$ should try to utilize in order to exploit undeveloped niche markets and push the digitization strategy. Maria replied that she would agree that crowdlending was an interesting trend, but nevertheless, she did not believe it to be a cash cow. She pointed out how different crowdfunding was compared to TBOS's business. First, the platform itself, which would have to be integrated into TBOS's banking system, would be needed. Second, the employees were experts for the traditional banking business and did not have any experience with crowdfunding or online crowds, TBOS would have to hire external experts. Third, she mentioned the unknown impact the new product might have on TBOS's brand. No one would know how the Swiss market and the customers would react when they would start such a new product. Fourth, TBOS would have to school all sales representatives, branch employees, and call center agents. Maria concluded that crowdfunding seemed to be fascinating but it would be an insignificant product that only aimed at certain niche markets that would not represent TBOS's core markets. Thus, it would not be possible to create a profitable business model. Further, Maria asked why TBOS should cannibalize its current products, which were quite successful. To her, the whole idea would just result in extensive effort, high costs, and unfulfilled expectations, for which someone would have to take responsibility. Maria closed: "Our evaluation showed clearly that the crowdfunding market is too small." Nick replied by asking whether she knew Bill Gates' quote, "Banking is necessary, banks are not." Maria added mockingly: "Crowdlending won’t threaten our business model, Nick!"

\section{Revamping Crowdlending at TBOS - A Partnering Approach?}

After the meeting with Maria, Nick was quite disenchanted. He thought about Maria's last sentence, which reminded him of the story of digital photography that he was taught during his studies. Starting with a poor resolution and low picture quality at the bottom of the market, incumbents laughed at this new trend while they continued to focus on their superior classic photography. Over time, digital photography improved and took over the market, while former market leaders, such as Kodak, were forced out of the market. Nick pondered that maybe it would just not be possible to see which impact crowdfunding might have on their life and business. He hurried to see Alex in order to tell him about the meeting. Nick remembered his Silicon Valley experiences. In Silicon Valley, the ultimate goal for all start-ups is growth. They want to capture a specific market niche and then try to outgrow all competitors so that they cannot be pushed out of the market anymore. He had seen many start-ups that teamed up with grown-up companies like TBOS in order to increase their business. It came to his mind that it might be worth exploring the option of collaborating with an already established crowdfunding platform. In so doing, TBOS could potentially overcome the burdens and the internal resentments while engaging in the market. "Nick, this is a very interesting idea! I will screen the crowdfunding scene and will try to schedule meetings with the most promising platforms. Being one of the biggest banks in Switzerland, there should be something that we could offer to them", Alex replied.

Alex immediately started his market research. Two days later, he presented his findings to Nick. He reported that so far, crowdfunding and especially crowdlending in Switzerland were still in their infancy. No platform was dominating the market in Switzerland so far. Therefore, he also screened the markets of neighboring foreign countries. In Germany, there were several platforms that had already established themselves in the market, achieving significant growth and starting to expand to foreign countries. In particular, the crowdlending platform LendingHouse seemed appropriate for a partnership as they had already expanded to five different countries in Europe by establishing partnerships with local partners. Nick was excited about the findings and proposed to get in touch with LendingHouse soon in order to find out whether they were interested in a partnership with TBOS and the Swiss market.

It did not take long for Nick to get in touch with Chris, the CEO of LendingHouse (see Exhibit 5). One day later, they arranged a conference call. Nick reported about his situation and that he was currently having a closer look on crowdlending. He explained that he thought it might have a huge impact on the financial service industry, but it would be hard to say whether it would rather be a substitute or complement. He struggled to assess how disruptive and sustainable this trend would actually be. Nick mentioned his assumption that TBOS was not the only bank that was investigating the topic and exploring possible 
opportunities at that time. Nick addressed Chris whether he, as CEO of the leading platform in the market, could share some of his experiences with him. Chris replied: "Well, first, thank you for contacting me. We are always interested in an exchange of experiences. That is what successful start-ups do, right?" Chris laughed and reported about the tremendous growth crowdlending had experienced over the last few years. Nevertheless, he was unable to say whether it would be a sustainable substitution for banking products, but he stated that he was sure that crowdlending would establish itself as a serious funding alternative. He proudly reported that LendingHouse was able to serve niche markets that could not be served by banks so far, due to risk, volume, and complexity, and they assumed this growth to continue or even accelerate. He continued that besides private capital givers, more and more institutional capital givers would discover the opportunities these markets provide and invest billions through crowdlending platforms.

Nick asked directly how LendingHouse could serve these markets, while banks seem to fail doing so. Chris explained that the Internet, and related phenomena such as big data, would enable them to profitably serve these niche markets. LendingHouse would exploit the increasing skepticism toward banks and provide a more transparent and democratic funding alternative. As opposed to banks, they would serve a different purpose within the financial intermediation process. Instead of striving for arbitrage revenues by pooling money from capital givers and lending it to capital seekers on their own account, LendingHouse would directly connect capital givers and capital seekers for a certain fee. Nick interrupted and asked how LendingHouse was able to handle this complex business model. Chris replied that LendingHouse would not provide the services all alone. Their platform would represent their face to their customers, but in the back office, they had several partners who were integrated into a service system in which also banks would represent crucial partners. LendingHouse would work with local banks in every country in which they had expanded so far, as it was important to have someone with local insights. Additionally, involving a bank would be a trust-building element. Furthermore, in many countries, a bank would be needed for being able to perform financial intermediation due to regulatory reasons. Thus, banks already had competencies that were necessary in order to perform the crowdlending service provision and the banks could take different roles within the service system. Some of LendingHouse's bank partners engaged as institutional capital givers, meaning that they would invest a great amount of money in their credit projects as they could offer very competitive interest rates. Other banks would take a more active role and provide some of the services in the service system, for example payment or sales support. The role would depend on the bank's intentions. "What do you think are the banks' intentions", Nick wanted to know. "Shouldn't you know this better than me, Nick", Chris joked and continued to explain that he thought banks would mostly hope for profits from a huge, unexploited market niche. Additionally, due to the extreme low-interest phase, they would try to become more independent from the interest business and boost their image in terms of digitization and innovativeness. Chris stated: “I think, I don't have to mention that most banks are not very innovative and have a very high backlog in handling the opportunities the Internet and digitization provides. They hope that engaging in an innovative business, such as crowdlending, will improve their image for customers and employees."

Nick recognized that he hardly knew anything about crowdlending, LendingHouse, and the opportunities for TBOS. He knew he had some homework to do. As his final question, Nick was curious to ask Chris whether LendingHouse was interested in entering the Swiss market and whether TBOS might be a suitable partner for them. Nick was delighted to hear that LendingHouse had recently had a closer look at the Swiss market and even considered TBOS as suitable partner. Chris stated they were very interested in deepening the exchange and he suggested Nick to evaluate what TBOS's intentions and major goals might be and how TBOS imagined a possible partnership. After the call, Nick was both excited, as he might have identified a way to square the cycle - finding a way to profitably use crowdlending with minimal involvement of the bank - and exhausted when he thought about the mountain of work and the stressful and Sisyphus-like meetings he would have to make in order to convince his organization.

"How was the call with LendingHouse", Alex asked when he met Nick next day. Nick took a deep breath and reported that he had learned a lot and they definitely had some work to do before they could proceed with their idea. Crowdlending turned out to be way more complex as it seemed to appear on the surface. Nick explained that the key to be successful in the crowdfunding business was to create competitive service systems in which each partner would bring in their specific competences. Banks might take different roles in such service systems and offer some services such as payment processing or sales support, or might just invest in the credit projects within their investment portfolios. "I think we could try another attempt for positioning crowdlending within $T B O S$ if we are able to work out a compelling collaboration with 
LendingHouse. However, the feasibility study already presented very good reasons why TBOS should engage in crowdlending and was not further proceeded by our executives. The market clearly indicates that more and more customers become open to and fascinated by fintech innovations such as crowdfunding", Nick concluded. Nick and Alex figured out they had to elaborate on two things: First, they needed to design a compelling service system with LendingHouse and a way to overcome the internal challenges with such a partnering approach. Second, they needed to elaborate on the innovative potential of crowdlending for TBOS, which seemed to be most critical. The new crowdfunding attempt would only be successful if the innovation team was able to show the advantages of engaging in the crowdfunding market more clearly to the management. "The problems we are facing here are not unique to crowdfunding but seem to be applicable to most digital innovations that are currently being developed at TBOS. If we are able to position our initiative as a means to overcome some of them, they might show more interest in the topic", Nick closed.

\section{Assessing What Makes Crowdfunding Different}

During the next weeks, Nick and Alex got down to work, did much research regarding crowdfunding, and even held exhausting workshops within various departments, such as Product Management or Compliance \& New Business, in order to assess TBOS's position. After having signed a non-disclosure agreement, they constantly exchanged with LendingHouse in order to understand how crowdlending diverged from TBOS's existing products and services and to unravel the fundamental mechanisms that make crowdfunding service systems successful and render crowdfunding an innovative alternative to traditional financial products. They elaborated these reasons in a memorandum, which was meant to serve as the basis for decisionmaking. In the following, an extract of this memorandum describes the most important findings:

1. Digitization of business operations: Being a pure online player, LendingHouse's operations are mostly digitized. Besides few regulatory provisions, the whole credit processing at LendingHouse is performed online. They are constantly looking for ways to digitize the rest in order to make the credit processing faster and more convenient for both capital seekers and capital givers. Therefore, they are proactively staying in exchange with financial market authorities in order to evaluate their new approaches. LendingHouse has improved the credit processing to such an extent that they are able to pay out the loan within 48 hours after the loan application has been submitted. At TBOS, this process needs at least two weeks. The vast digitization of business processes also gives raise to automation. For instance, credit scoring, that is, predicting credit default risk and determining associated credit interests for capital givers, is the most crucial competence for all kinds of financial intermediaries issuing credits. Applying an extensive big data approach by combining traditional credit scoring with behavioral user data, LendingHouse is able to predict credit default with higher accuracy than most traditional banks. Due to their offline distribution approach, banks lack access to these behavioral data, and thus, they do not have the opportunity of collecting and analyzing behavioral information. Thus, their risk assessment is heavily built on third-party services such as credit risk agencies and offline risk assessment. In contrast, LendingHouse includes a vast amount of behavioral user data that is generated by capital givers. In this vein, they include more than 500 data points in predicting credit default, for example the number of spelling errors within the credit application, previously visited websites, or the time of the application. This information is combined with traditional risk scorings by applying a complex and dynamic algorithm in order to improve the predictability of the capital seeker's default risk. The inclusion of new data points and the refinement of the risk scoring algorithm is a continuous challenge and the reason why LendingHouse hired leading risk experts and data analysis experts.

2. Co-creation: As the funding decision and the accompanying credit default risks are taken by the crowd, that is, a sufficient number of capital givers that fund a project, crowdfunding is considered to be more democratic and fair. Thus, LendingHouse supports the value co-creation between capital givers and capital seekers. Further, digitization enables LendingHouse to engage its crowd of capital givers and seekers in service provision. Applying Web 2.0 and co-creation mechanisms, for example commentaries, social media links, and video pitches, allows capital givers and seekers to directly interact while also making crowdfunding being perceived more contemporary, transparent, and entertaining, as it operates in the way the users are expecting it in the digital age. On the one hand, capital givers are mainly motivated by attractive returns and the innovative platform concept. They appreciate the selfdetermination LendingHouse offers, as they can build their own portfolios that meet their individual 
requirements in terms of volume, duration, and risk affinity. In order to enable, foster, and secure the direct interaction and, for example, the portfolio building, LendingHouse is engaged in the value cocreation by acting as neutral, trustworthy, and objective partner that ensures integrity, veracity, and legal compliance in order to manage risks and uncertainties.

3. Multi-sided platform business: Matching supply and demand for capital is the major task of crowdfunding platforms. As Nick and Alex described it, it resembles a dating platform for capital givers and seekers. In this vein, crowdfunding can be considered as two-sided market where capital seekers and capital givers are interacting on a platform that acts as intermediary. In contrast to banks, they do not borrow, pool, and lend money on their own account, but enable the effective and efficient matchmaking of capital givers and capital seekers. As a consequence LendingHouse does not carry any default risk as it is collectively carried by the crowd of capital givers. Thus, crowdfunding platforms do not make profits on the basis of an arbitrage interest business, but for successfully connecting capital givers and seekers. They take a matchmaking fee of 3 percent of the requested loan volume, which has to be paid when a project has been successfully funded by capital seekers, or 1 percent of each payback by the capital givers, respectively.

4. The long tail of the financial service industry: Digging deeper and deeper into the crowdfunding market, Nick and Alex figured out that most crowdfunding platforms seem to serve market niches that have not been served by banks or other traditional financial service intermediaries, for example credits for high-risk groups such as start-ups that have irregular earnings, high failure rates, and frequently lack a financial history. Other crowdfunding platforms frequently cover innovative niche products that are developed for specific interest groups instead of the mass market. LendingHouse mainly offers credits to capital seekers for private purposes, such as consumption, holidays, marriages, or rescheduling. The average credit volume is around 13,000 EUR. As credit volumes are low and default risks are high, these target groups have not been extensively served by banks and other traditional service providers. However, due to the digitization of business processes, the big data approach to risk scoring, as well as not taking any credit default risks, LendingHouse was able to cut the costs per loan significantly and is able to offer these low-end loans in a profitable way. This has caused an enormous growth throughout the last years and enables the quick expansion to new market niches and foreign countries. Capital seekers pay interests ranging from 2.10 percent to 14.50 percent for private capital seekers depending on risk rating, payback duration, and credit volume. Besides, LendingHouse increased its offerings for self-employed and small businesses. Both markets are usually not served by major banks, as they are too risky or too small to be profitable. LendingHouse offers business loans starting from 10,000 to 250,000 EUR (100,000 EUR on average) with 4.0 percent to 16.00 percent of interests to be paid.

\section{Creating Crowdfunding Service Systems}

After having worked out the mechanisms that render crowdlending an innovative service, Nick and Alex elaborated on the services crowdlending platforms usually offer and that serve as single building blocks in such service systems mentioned by Chris. It becomes clear that it is not only the service itself, but the overall service system that represents the disruptive innovation.

In such a service system, several - very often more than two - actors are involved in creating value propositions and offering services (Peters 2016; Peters et al. 2015). Therefore, the stakeholders of the service system deliver own services that require resources and need to be integrated into the overall offerings. In this context, LendingHouse acts as the orchestrating and enabling entity of the crowdlending service system. Hereby, it bundles the competencies of several partners within the service system. LendingHouse represents the face to the user, while the back office processes are performed by partners of the service system. This enables the exploitation of typical network benefits, such as the expansion to new markets or market segments, the integration of up- or downstream value creation stages, establishing sustainable partnerships, and acquiring new competences. Additionally, it enables the creation of advantages in terms of efficiency and effectiveness, the focus on core competencies, the variabilization of fixed costs, and the reduction of complexity. The success of the crowdfunding service is determined by the interplay of its service system's stakeholders and the integration of resources. By design, the interplay focuses on the joint user-centric value co-creation of all service system stakeholders and the resource integration aims at realizing efficient processes (Peters et al. 2016). 
The crowdfunding service system of LendingHouse consists of twelve services (see Table 1) that might be performed by different partners and are bundled to one crowdlending service bundle.

\section{Matchmaking}

\section{Table 1: Overview of Services provided at LendingHouse}

Interconnection and intermediation of capital seekers \& givers in order to ensure successful funding, provide information, and register funding decisions. Therefore, LendingHouse provides information about the capital seeker, such as use of funds, credit risk, and additional personal information.

\section{Contracting \& compliance}

Automated and standardized online contracting and underwriting processes for the credit agreement between capital givers and seekers are provided in order to enable fast and efficient credit processing and to ensure the compliance of regulatory requirements. As LendingHouse does not have a branch network, they rely on digital solutions.

\section{Customer support}

Capital seekers \& givers are served and assisted through various channels throughout the complete credit processing in order to emphasize the low level of bureaucracy, to enhance the customer relationship and the trust in the platform, to overcome initial barriers, and to clarify customer issues. For example, LendingHouse calls each new capital seeker or giver in order to clarify possible questions or uncertainties. Therefore, Lending House tries to overcome the anonymity of the Internet and the lack of a physical branch network where customers can come by in order to place inquiries.

\section{Risk scoring}

In order to keep default rates down, capital seekers are evaluated regarding their creditworthiness, credit history, and trustworthiness. Therefore, traditional forms of risk scoring (information provided by credit scoring agencies) are extended by the analyses of behavioral information coming from data analytics (online times, project description, cookies, etc.). The risk scoring procedure represents one of the most critical competitive edges, as high default rates would threaten LendingHouse's reputation.

\section{Authentication}

In order to prevent fraud, money laundry, and to meet legal regulations, comprehensive online identification and authentication processes of both capital seekers and givers are applied. Due to the lack of a branch network, LendingHouse has to develop digital solutions. Therefore, innovative procedures are developed and presented to market authorities.

\section{Crowd activation}

Online and offline marketing is needed in order to attract, activate, and balance capital seekers and givers, and by that, to ensure funding success and attractive interest rates as well as to generate buzz. Therefore, LendingHouse has to evaluate the market situation in real time in order to immediately activate a certain customer group via various channels.

\section{Sales}

Besides promotional activities, leads, in terms of capital seekers, can be purchased from, for example, banks that cannot serve the clients themselves but want to provide alternative ways of funding or investing. Additionally, LendingHouse maintains a network to all kinds of institutional capital givers that invest larger sums. By that, LendingHouse can ensure a 100 percent funding rate that is independent of private capital givers.

\section{Investor relations}

As capital seekers and givers are interconnected directly, certain functionalities enable communication between them. Additionally, overviews of performance and quality of the investment portfolios are provided.

\section{IT operations}

The platform is the face to the users and the digital point of contact between capital seekers and givers. Further, complex back office processes are performed in order to orchestrate the service system and all integrated partners.

\section{Payment}

A fast, reliable, trustworthy, and efficient flow of money between capital seekers and givers as well as between the service system partners is crucial for a sustainable platform success. 


\section{Banking}

For performing the credit processing, an account infrastructure is needed. Additionally, to ensure a fast credit processing, ex ante financing and exclusive access to credit information for the bank might be necessary.

Dunning \& debt collection

In order to minimize the risk of investment losses, which affects the trustworthiness of the platform, effective dunning and debt collection are necessary in the case of debt default.

Table 1: Overview of Services provided at LendingHouse (Haas et al. 2015)

\section{Enforcing the Partnering Decision}

After finishing the memorandum, Nick arranged a meeting with his and Maria's team in order to present his and Alex's findings and discuss the next steps. Nick shortly presented the outcomes of the memorandum and the re-examination of the potentials of crowdlending to TBOS. After this introduction, he proceeded: "I think that building a service system with LendingHouse would enable us to exploit this market profitably. Today, I would like to discuss with you what we should focus on and whether we should engage in crowdlending or not. LendingHouse expects our decision and time is running as I'm pretty sure that other banks have recognized the potentials of crowdlending as well. Time to market matters!"

During the meeting, they evaluated pros and cons and decided that, on the one hand, an own crowdlending engagement would help to revitalize TBOS's current credit products and provide opportunities for their digitization strategy. On the other hand, it would contain financial and reputational risks, which could not easily be overseen so far. Against this background, they particularly discussed that large new niche markets could be exploited by that, such as the market for small private or business loans. The business case was assessed to be profitable and possibly increasing fast. However, by taking a short-term perspective, figures were rather small such that an investment in a crowdlending business might resemble a bet on the future market development. Everybody agreed that partnering with LendingHouse represented a viable way to engage in the crowdlending business. Nevertheless, the costs for managing the partnership and the service system were hard to assess and would remain a black box that represented a risk for the business case, as TBOS lacked experience with this kind of partnership. Although TBOS was the larger partner in terms of financial resources, the know-how for operating the crowdlending offering was owned by LendingHouse, which would actually make TBOS the junior partner in this partnership, as TBOS would not be able to perform such a platform on its own. The meeting participants concluded that such an engagement might cause risks that could not be controlled completely. This included reputational risks as it could not be assessed how the market would react when TBOS would engage in crowdlending. Further, it implied regulatory risks as no specific regulation for crowdlending existed so far. In this context, the particularities of service systems played a significant role. It was not only the bank, its own resources, and the customers, as in a traditional setting of financial services, but also the new roles in the crowdlending service system, such as of the platforms and intermediaries, which had to be considered. This might make substantial changes of the business model necessary, which might have negative effects on the business case.

At the end of the meeting, Maria rose to speak: "Nick, you know I have been very critical of this idea and I still am. I can't believe that this phenomenon can sustainably affect the financial service industry. Of course, these start-ups did pick up some of our weaknesses and built successful business models around them. But don't forget that the attributes we are arguing and criticizing are major reasons why we have been so successful in the past. Our clients appreciate that we are a reliable, constant, and stable partner, who takes care of their money, consults them with our expertise, and provides solutions for their financial needs. We protect our clients from over-indebtedness instead of funding loans for clients who can't afford them. Last, due to our branch network and our personal financial consultants, we do have a personal relationship to our clients instead of just being an anonymous website. You should never forget that our clients entrust their money to us and this is a very sensible topic. A failure by engaging in a doubtful innovation, such as crowdlending, might cause severe damages to our brand." 
Nick looked back at the past month, the tough job, and how this whole idea had taken shape. He was surprised about how the idea had become much more complex than he had ever expected. He summarized the results of the meeting: "Thank you all again for your constructive collaboration. I think we all learned a lot about crowdfunding and how start-ups invade and try to disrupt our business. Additionally, we experienced how TBOS is able to cope with these new competitors and how we are able to quickly use innovations and opportunities. Allow me the comment, this should make us think." He proceeds: "I know there are some risks and issues. We should take them seriously as we will neither be able to eliminate them all, nor are we able to overview how crowdlending will develop in the future. We sufficiently discussed all these issues over and over. After all, we have to decide whether we are willing to take these risks and believe that the opportunities exceed the risks or not."

Nick elaborated that the whole team now had to decide whether to pursue this idea any further or to terminate it. He expressed that if they decided to pursue this idea, the next steps would be to decide how the best service system for successful crowdlending looked like and how TBOS could contribute to and benefit from the service system.

After he finished, Nick took a look out of the window of the meeting room and looked at the snow-covered mountains. He recognized that it had been more than half a year ago when he had read the newspaper article and took an interest in this idea. He felt tired when he thought about how slow things evolved at $T B O S$ and how much work was still to do. 


\section{Appendix}

\section{Exhibit 1: Crowdfunding Types}

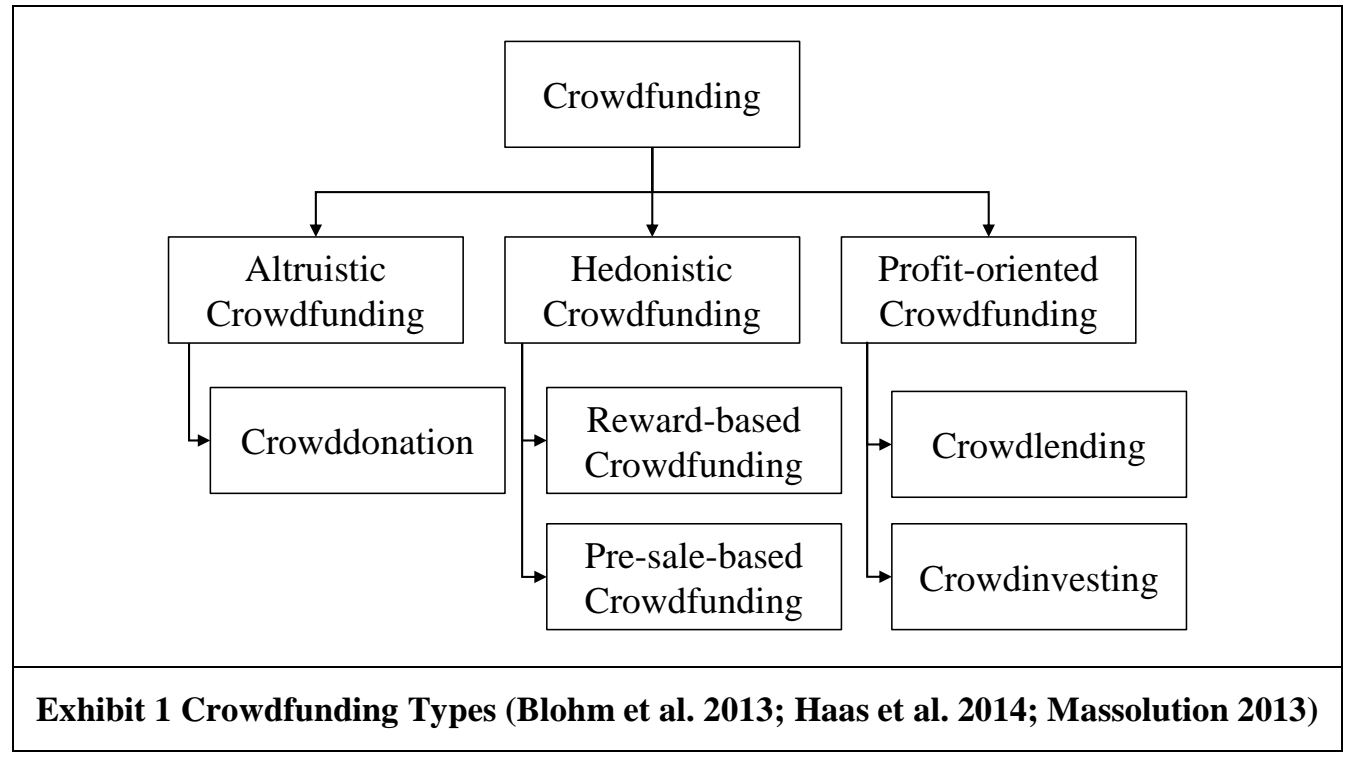

\section{Exhibit 2: Development of the Global Crowdfunding Market}

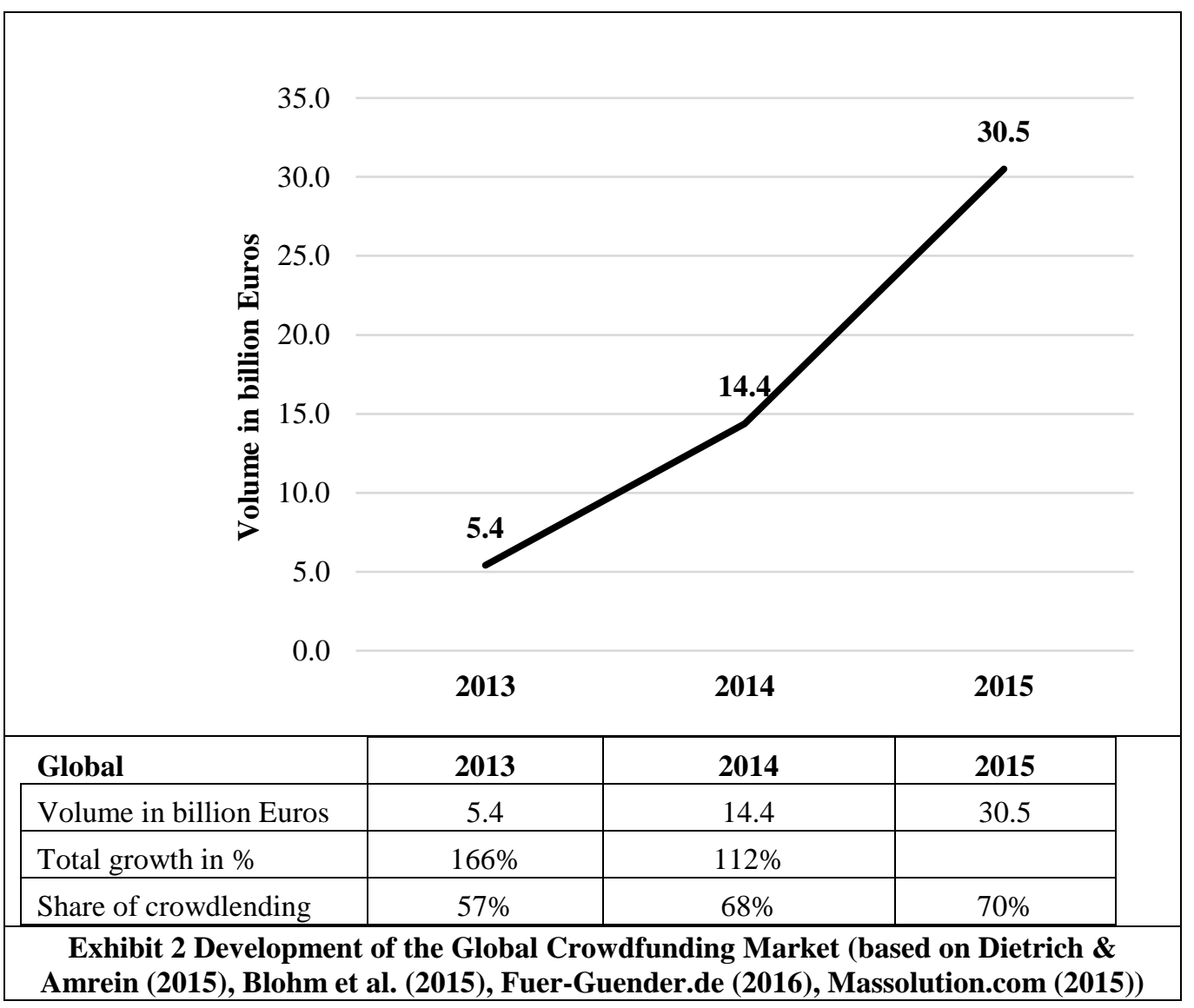


Exhibit 3: Development of the Crowdfunding Markets in Switzerland and Germany

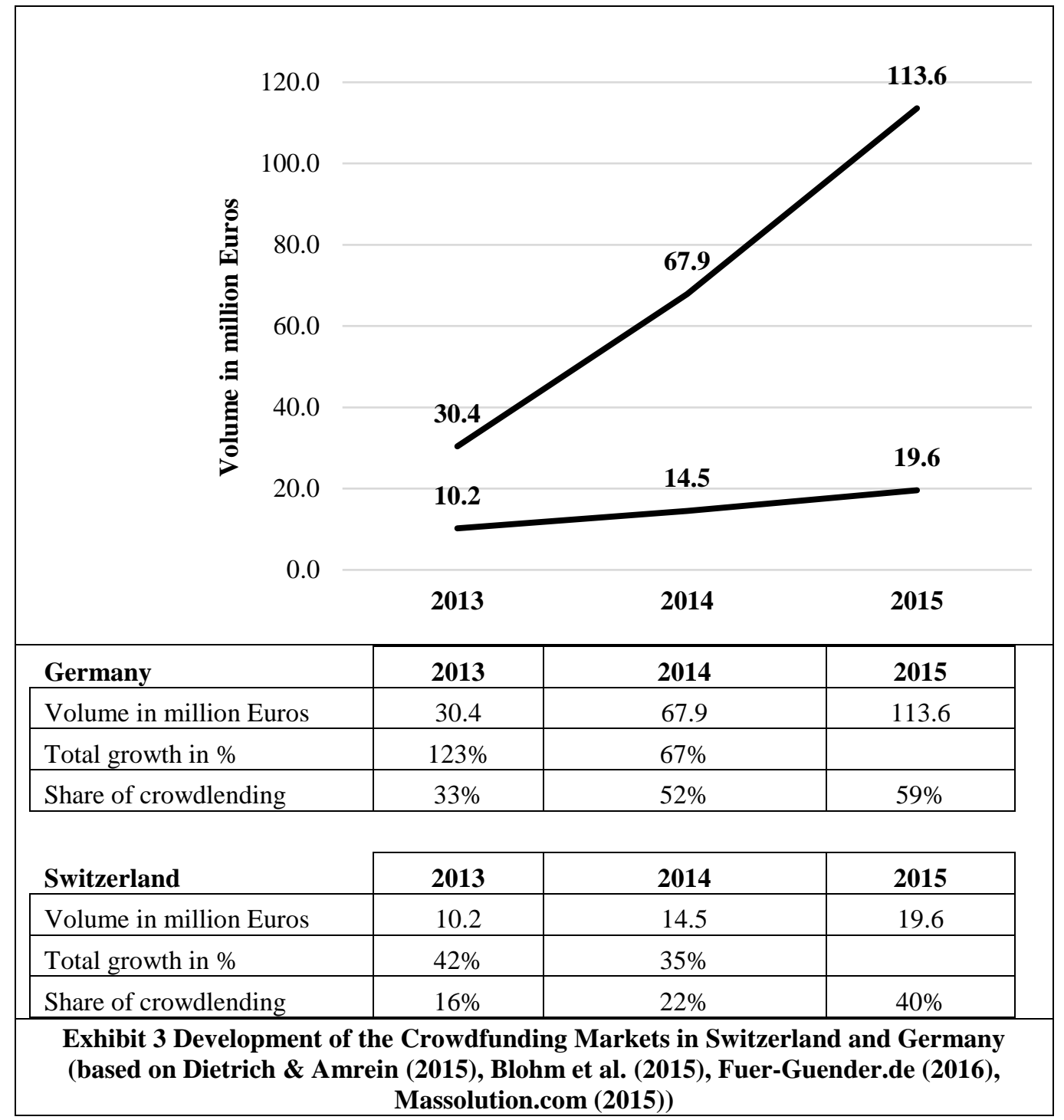




\section{Exhibit 4: Organigram of TBOS}

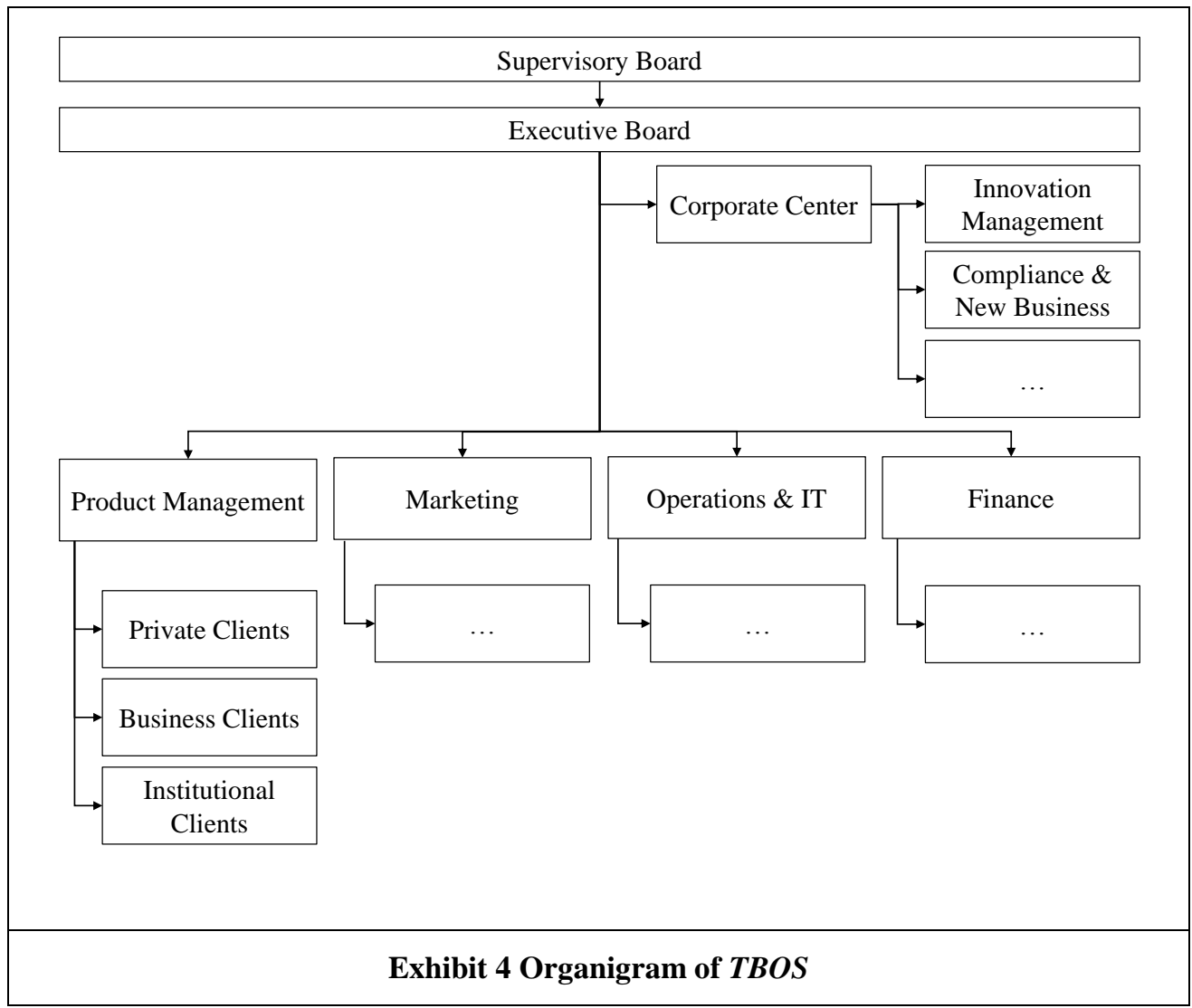

\section{Exhibit 5: Organigram of LendingHouse}

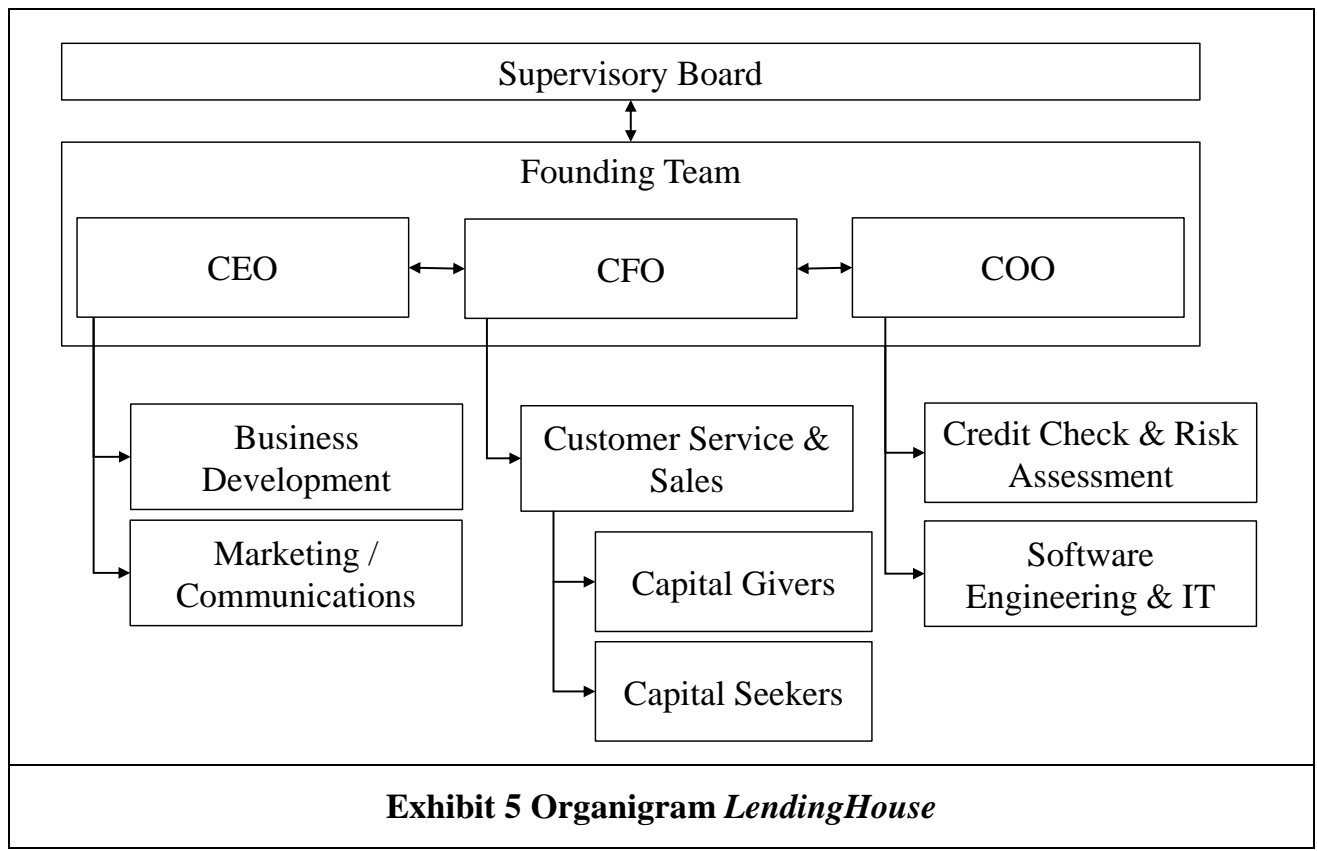




\section{References}

Blohm, I., Leimeister, J. M., Wenzlaff, K., and Gebert, M. 2013. Crowdfunding-Studie 2013/2014. Berlin: epubli.

Blohm, I., Sieber, E., Schulz, M., Haas, P., Leimeister, J. M., Wenzlaff, K., and Gebert, M. 2015. Crowdfunding 2020 - Komplement Oder Substitut Für Die Finanzindustrie? Norderstedt: BoD - Books on Demand.

Dietrich, A., and Amrein, S. 2015. Retrieved 15.05.2016, from https://blog.hslu.ch/retailbanking/files/2015/o5/Crowdfunding-Mon_Deutsch_Web.pdf

Fuer-Gruender.de. 2016. "Crowdfinanzierung in Deutschland - Ausgabe: Nr. 1/2016." Retrieved 15.04.2016, from https://www.fuergruender.de/fileadmin/mediapool/Unsere_Studien/Crowdfinanzierung_Monitor_2015_FuerGruender.de_Dentons.pdf

Haas, P., Blohm, I., and Leimeister, J. M. 2014. "An Empirical Taxonomy of Crowdfunding Intermediaries," International Conference on Information Systems (ICIS), Auckland, New Zealand.

Haas, P., Blohm, I., Peters, C., and Leimeister, J. M. 2015. "Modularization of Crowdfunding Services Designing Disruptive Innovations in the Banking Industry," in: 36th. International Conference on Information Systems (ICIS). Fort Worth, USA.

Massolution. 2013. "2013cf - the Crowdfunding Industry Report." Retrieved 05.05.2016, from http://www.crowdsourcing.org/editorial/2013cf-the-crowdfunding-industry-report/25107

Massolution.com. 2015. "2015cf - the Crowdfunding Industry Report." Retrieved 15.04.2016, from http://www.crowdsourcing.org/editorial/global-crowdfunding-market-to-reach-344b-in-2015predicts-massolutions-2015cf-industry-report/45376

Peters, C. 2016. Modularization of Services - a Modularization Method for the Field of Telemedicine. Kassel University Press.

Peters, C., Blohm, I., and Leimeister, J. M. 2015. "Anatomy of Successful Business Models for Complex Services: Insights from the Telemedicine Field," Journal of Management Information Systems (32:3), pp. 75-104.

Peters, C., Maglio, P., Badinelli, R., Harmon, R. R., Maull, R., Spohrer, J. C., Tuunanen, T., Vargo, S. L., Welser, J. J., and Demirkan, H. 2016. "Emerging Digital Frontiers for Service Innovation," Communications of the Association for Information Systems (39:1).

\section{Teaching Note}

Educators may contact the first author of this teaching case via email to obtain a copy of the supplementary teaching note. 